\title{
The decline of Africa's largest mammals
}

\author{
Did hominins play a role in the loss of megaherbivores? \\ By René Bobe 1,2,3 and Susana Carvalho 1,2,3,4
}

The human species is causing profound climatic, environmental, and biotic disruptions on a global scale. In the present time (now called the Anthropocene), most species of large terrestrial herbivores are threatened with extinction as their populations decline and their geographic ranges collapse under the pressure of human hunting, poaching, and encroachment (1). Although the scale of ongoing anthropogenic ecological disruptions is unprecedented, human-driven extinctions are not new: There is strong evidence that humans played a major role in the wave of megafaunal losses at the end of the Pleistocene, between about 10,000 and 50,000 years ago (2). But when did humans, or our ancestors, begin to have such a profound effect on large herbivores to the point of causing extinctions? On page $\mathrm{xxx}$ of this issue, Faith et al. (3) provide evidence to help answer this question. They track the number of megaherbivore species (mammals weighing more than $1000 \mathrm{~kg}$ ) in eastern Africa from the late Miocene, about 7 million years ago, to the present. Their analysis indicates that megaherbivore diversity began to decline in the early Pliocene, about 4.6 million years ago.

Hominins--species on our side of the evolutionary divergence that separated us from the chimpanzees--first appeared in Africa in the late Miocene, about 7 million years ago. The late Miocene was a time of global climatic and environmental change, with an expansion of grasslands (with $\mathrm{C}_{4}$ photosynthesis) in tropical latitudes and an increasing frequency of fires (4). At that time, large mammals were abundant in eastern Africa. At Lothagam, for example, in the Lake Turkana Basin of Kenya, there were 10 species of megaherbivores (5), in-

Primate Models for Behavioural Evolution Lab, Institute of Cognitive and Evolutionary Anthropology, School of Anthropology, University of oxford, oxford, UK. ${ }^{2}$ Gorongosa National Park, Sofala, Mozambique. ${ }^{3}$ Interdisciplinary Center for Archaeology and Evolution of Human Behaviour (ICAREHB), Universidade do Algarve, Portugal. ${ }^{4}$ Centre for Functional Ecology-Science for People \& the Planet, Universidade de Coimbra, Portugal.

rene.bobequinteros@anthro.ox.ac.uk cluding the earliest records of the elephant family, Elephantidae. Near Lothagam is the early Pliocene site of Kanapoi, with a rich fossil record dated to about 4.2 million years ago. Kanapoi has the earliest record of the hominin genus Australopithecus (6), which coexisted with at least 11 species of megaherbivores: five proboscideans, two rhinocerotids, two giraffids, and two hippopotamids, along with a diverse fauna of large carnivores that included giant otters, hyenas, two species of saber-tooth felids, and three species of crocodiles (7). Kanapoi, at about 4.2 million years ago, with an area of $32 \mathrm{~km}^{2}$, had twice the number of megaherbivore species as the entire continent of Africa today. Among the five species of proboscideans, there were the ancestors of the modern African and Asian elephants, Loxodonta and Elephas, respectively. From their first appearance in eastern Africa, both elephants fed predominantly on increasingly abundant grasses (8). It is probable that these elephants and other megaherbivores played a beneficial role for early hominins by opening up wooded environments, thereby resulting in the mix of woodlands and grasslands where hominins seemed to thrive $(5,9)$. Thus, at Kanapoi and other sites in Africa during the Pliocene (5.3 to 2.6 million years ago) early hominins lived in proboscidean-dominated landscapes. These hominins were relatively small $(\sim 45 \mathrm{~kg})$ and left no known traces of tool-assisted behaviors. They were primarily terrestrial omnivores that used trees for refuge and food, and it is likely that they competed for resources with other mammals like suids and monkeys, but had little impact on megaherbivores. Moving forward in time from 4.2 million years ago to 1.5 million years ago, three hominin species, including Homo erectus, possibly Homo habilis, and Paranthropus boisei, inhabited another set of sites in the Lake Turkana Basin. By then, hominins were procuring animal resources by using stone tools, as the abundant archaeological evidence makes clear, and they were probably beginning to use fire (10). There is no evidence of systematic hunting of very large mammals, so direct effects of hominins on megaherbivores were limited. But if hominins were beginning to use fire $1.5 \mathrm{mil}$ lion years ago, what was the impact on the landscape and on the foraging patterns of the largest terrestrial mammals?

Early hominins in eastern Africa lived in a rapidly changing landscape, in which grasslands were becoming more prevalent, and a whole suite of grazing mammals were rapidly evolving and diversifying (11). Elephas was successfully adapting to these changing African landscapes during the Pleistocene when it became a dominant megaherbivore. But even this widely distributed and abundant grazer became extinct in Africa toward the late Pleistocene, surviving in Asia until today. Loxodonta became rare after the early Pliocene, only to reemerge in the middle and late Pleistocene as a browser and mixed-feeder rather than a grazer (8).

Faith et al. propose that expanding grasslands, declining concentrations of atmospheric $\mathrm{CO}_{2}$, and competition with smaller browsing mammals all contributed to the decline of megaherbivore species richness. However, it is not clear what ecological roles hominins played throughout the long evolutionary history of megaherbivores in Africa, and how these roles changed over time and varied across geographic space. Another question is when hominins became systematic predators of animals larger than themselves. Could periods of marked seasonality, with peaks of drought, result in a "fallback" predation strategy, whereby carnivores preyed heavily on proboscideans? As documented in modern African landscapes (12), predation on young, vulnerable individuals in species with very slow life histories could have irreparable effects on the long-term viability of megaherbivore populations. As fires became more frequent beginning in the late Miocene (4), they may have altered landscapes and affected the foraging, ranging patterns, and dispersal of large herbivores. Also, what new pathogens emerged with the new landscapes of eastern Africa and what their effect was in the oldest and youngest individuals within these large mammal populations? The causes of megaherbivore decline are probably complex, multidimensional, and varied across time 
and space. The precise timing of key hominin behavioral innovations remains poorly constrained by the current archeological and paleontological records. Indeed, the role that hominins played is still open to question.

\section{REFERENCES AND NOTES}

1.W. J. Ripple et al., Science Advances 1, (2015).

2.C. Sandom, S. Faurby, B. Sandel, J.-C Svenning, Proceedings of the Royal Society B: Biological Sciences 281, (2014)

3.J. T. Faith, J. Rowan, A. Du, P. L. Koch, Science 362, XXX (2018)

4.W. J. Bond, Frontiers in Plant Science 5, 1 (2015).

5.L. Werdelin, W. J. Sanders, Eds., Cenozoic mammals of Africa, (University of California Press, Berkeley, 2010), pp. 1008

6.C. V. Ward, J. M. Plavcan, F. K. Manthi, New fossils of Australopithecus anamensis from Kanapoi, West Turkana, Kenya (2012-2015). Journal of Human Evolution, (2018).

7.J. M. Harris, M. G. Leakey, Eds., Geology and vertebrate paleontology of the early Pliocene site of Kanapoi, northern Kenya, (Natural History Museum of Los Angeles County, Los Angeles, 2003), vol. 498, pp. 132.

8.T. E. Cerling, J. M. Harris, M. G. Leakey, Oecologia 120, 364(1999).

9.J. Kingdon, in Mammals of Africa, J. Kingdon et al., Eds. (Bloomsbury Publishing, London, 2013), vol. 1, pp. 75-100.

10.G. L. Isaac, B. Isaac, Eds., Plio-Pleistocene Archaeology: Koobi Fora Research Project Volume 5, (Clarendon Press, Oxford, 1997), vol. 5 .

11.T. E. Cerling et al., Proceedings of the $\mathrm{Na}$ tional Academy of Sciences 112, 11467 (2015).

12.A. J. Loveridge, J. E. Hunt, F. Murindagomo, D. W. Macdonald, Journal of Zoology 270 523 (2006)

\section{ACKNOWLEDGMENTS}

We thank J. Kingdon and D. R. Braun for discussions on topics presented here.

10.1126/science.aav6883 